\title{
Controlled Arrival Machine Repair Problem with Working Vacation and Reattempts
}

\author{
Amita Bhagat \\ Department of Mathematics, \\ Jaypee Institute of Information Technology, Noida, India. \\ Corresponding author: amita.bhagat@jiit.ac.in \\ Rachita Sethi \\ Department of Mathematics, \\ G. D. Goenka University, Gurugram, India. \\ E-mail: rachusethi4.rs@gmail.com \\ Deepika Garg \\ Department of Mathematics, \\ G. D. Goenka University, Gurugram, India. \\ E-mail: deepika.garg@gdgoenka.ac.in
}

(Received March 26, 2020; Accepted July 11, 2020)

\begin{abstract}
This paper addresses machine repair problem (MRP) with M identical operating machines and control arrival policy. The server is unreliable, and can break down during service which is further repaired soon so as to avoid interruption with the service process. The server may go for working vacation in case all the customers are served. The transient analysis of machine repair problem has been done using numerical technique. Various performance measures have been derived. With the help of tables and graphs the numerical results have been shown. The present investigation find applications in various industrial and workshop situations like Automobile repair shop (ARS).
\end{abstract}

Keywords- Machine repair, F-policy, Unreliable, Working vacation, Retrial policy.

\section{Introduction}

Machining system is of great importance for human beings. The failure of machining system is quite common and has impact on productivity of the system. Many researchers have done a lot of work in the field of machine repair problem. For relevant work refer survey papers by Shekhar et. al. (2016), Shekhar et al. (2017). As the server is vulnerable to failure, machining system's random failure significantly impacts the machining system's efficiency. Many researchers have analysed queues with unreliable server. Ke et al. (2013) analysed MRP with unreliable multi repairman using recursive matrix approach. A transient queue with disaster was studied by Jain and Singh (2020).

Sometimes, a customer is not served due to unavailability of the server at the moment. These situations force customer to check for server again and make reattempts for service leading to retrial queues. The detailed account on retrial queues is available in the survey articles by Falin (1990), Artalejo (1999), Artalejo (2010) . Many researchers (Sherman and Kharoufeh, 2006; Choudhury and Ke, 2014; Li and Zhang, 2017) studied retrial queues with unreliable server. Morozov and Phung-Duc (2017) analysed multiclass retrial queue with classical retrial policy. Recently, Bhagat (2020) conducted research on a priority unreliable system with retrial and evaluated the system parameters using the Runge - Kutta technique. 
International Journal of Mathematical, Engineering and Management Sciences

Vol. 6, No. 1, 279-295, 2021

https://doi.org/10.33889/IJMEMS.2021.6.1.018

To keep a check on the arrival of the customers is also a disciplinary step for the efficient output. Various control policies are used for the mathematical modelling of queues with control rates. In order to avoid overloading of the server concept of F-policy has been used. According to this control policy, when the system capacity is full, the arrival of machines is stopped and the arrival is not permitted till the stage the queue length of the system reduces to threshold level say ' $\mathrm{F}$ ' after service. The analysis of transient behaviour of the model is also an interesting area for queue theorists. In order to analyse transient behaviour both analytic and numerical techniques can be adopted. Runge-Kutta has been most common technique used by researchers to study the time dependent behaviour of the model. Jain et al. ( 2012) analysed unreliable finite queueing system under various control policies. Wu et al. (2014) did optimal analysis of unreliable queueing model using controllable policies. The work of prominent experts (Wang and Yang, 2009; Wang et al., 2009; Jain and Bhagat, 2015) are notable in series of investigations based on F-policy. Sharma and Kumar (2017) and Sharma and Kumar (2020) investigated models with working vacation using RK method. Sethi et al. (2019) examined a queueing model with various threshold policies using Runge - Kutta method.

The server may also go for vacation or some leisure activities if no more customers are available. Bernoulli vacation, $\mathbf{J}$ vacations, working vacation, multiple vacations etc. are various kind of vacation policies usually adopted by a server. Here, the concept of working vacation has been used according to which, the server instead of completely going off for vacation, the server provides service but at a lower rate. Vacation queues have been immensely evolved since the work of Levy and Yechiali (1975). Many researchers have analysed queueing models with working vacation owing to its significance in machining environment, computer networks etc. The concept of working vacation in M/M/1 queueing system was introduced by Servi and Finn (2002). The related literature on working vacation queues can be found in survey by Chandrasekaran et al. (2016). Recently, MRP model with working vacation has been studied by Sethi and Bhagat (2019). Sethi et al. (2020) recently studied a machining system that includes the concept of N-policy and impatience.

In this study, R-K method is used to study the performance measures of queueing model under consideration. The manuscript is arranged as follows. The detailed model description with state transition diagram has been discussed in section 2. Mathematical formulation of the model is provided in section 3. In section 4, performance measures of the system are developed. The numerical analysis of the model is given in section 5. In section 6, the cost function has been developed and studied. Finally, section 7 draws a conclusion.

\section{Model Description}

Consider a machine repair model with $\mathrm{M}$ similar operating machines maintained by a single repairman. In order to prevent overloading on the machining system and to keep the machining system running smoothly, the control policy namely F-policy is incorporated.

\subsection{Assumptions}

The basic assumptions underlying the model are discussed below as:

- Arrival Process: The arrival process of the machines requiring service follows Poisson distribution with the state dependent arrival rate $(M-n) \lambda$.

- Retrial Process: The operating machines move to orbit if they find server busy or under repair 
International Journal of Mathematical, Engineering and Management Sciences

Vol. 6, No. 1, 279-295, 2021

https://doi.org/10.33889/IJMEMS.2021.6.1.018

and try for service with retrial rate $\gamma$ after some random amount of time until they find the server free. The retrial time of any operating machine is exponentially distributed and identically independent.

- F-policy: In order to control the congestion of machines in the system, the arrival pattern follows F-policy. According to this control policy, the arrival of the machines requiring services is stopped if total capacity has been achieved. This arrival is again initiated only if the number of machines in the queue have been reduced to threshold value, say $F$ after being served.

- Start-up Process: The arrival of the machines in the system according to F-policy restarts with start-up process which is exponentially distributed with rate $\xi$.

- Working Vacation: The server commences a working vacation, when the system is empty. It refers to the period in which the server works with different service rates i.e. lower service rate as compared to usual service rate instead of shutting down the services. The vacation duration follows an exponential distribution with mean $\frac{1}{\eta}$.

- Service Process: The incoming machines (customers) are offered services in the order of their arrival with different service rates depending on the state of the server. The service rates basically follow exponential distribution with rates as $\mu_{b}$ and $\mu_{V}$ during busy period and working vacation state respectively.

- Breakdown Process: The server can breakdown while servicing following exponential process with rate $\alpha$ while normal servicing and with rate $\alpha_{1}$ while on vacation.

- Repair Process: The failed server is repaired without any delays so as to continue the process of serving failed machines (acting as customers). The repair process also follows exponential distribution with rates $\beta$ and $\beta_{1}$ corresponding to the rupture of system during the normal busy period and working vacation period respectively. Operating machines are repaired according to the order of their breakdowns; i.e. FCFS discipline.

The state transition diagram for concerned machine repair model is given by Figure 1, which readily explains the functioning of the model and various policies. 
International Journal of Mathematical, Engineering and Management Sciences

Vol. 6, No. 1, 279-295, 2021

https://doi.org/10.33889/IJMEMS.2021.6.1.018

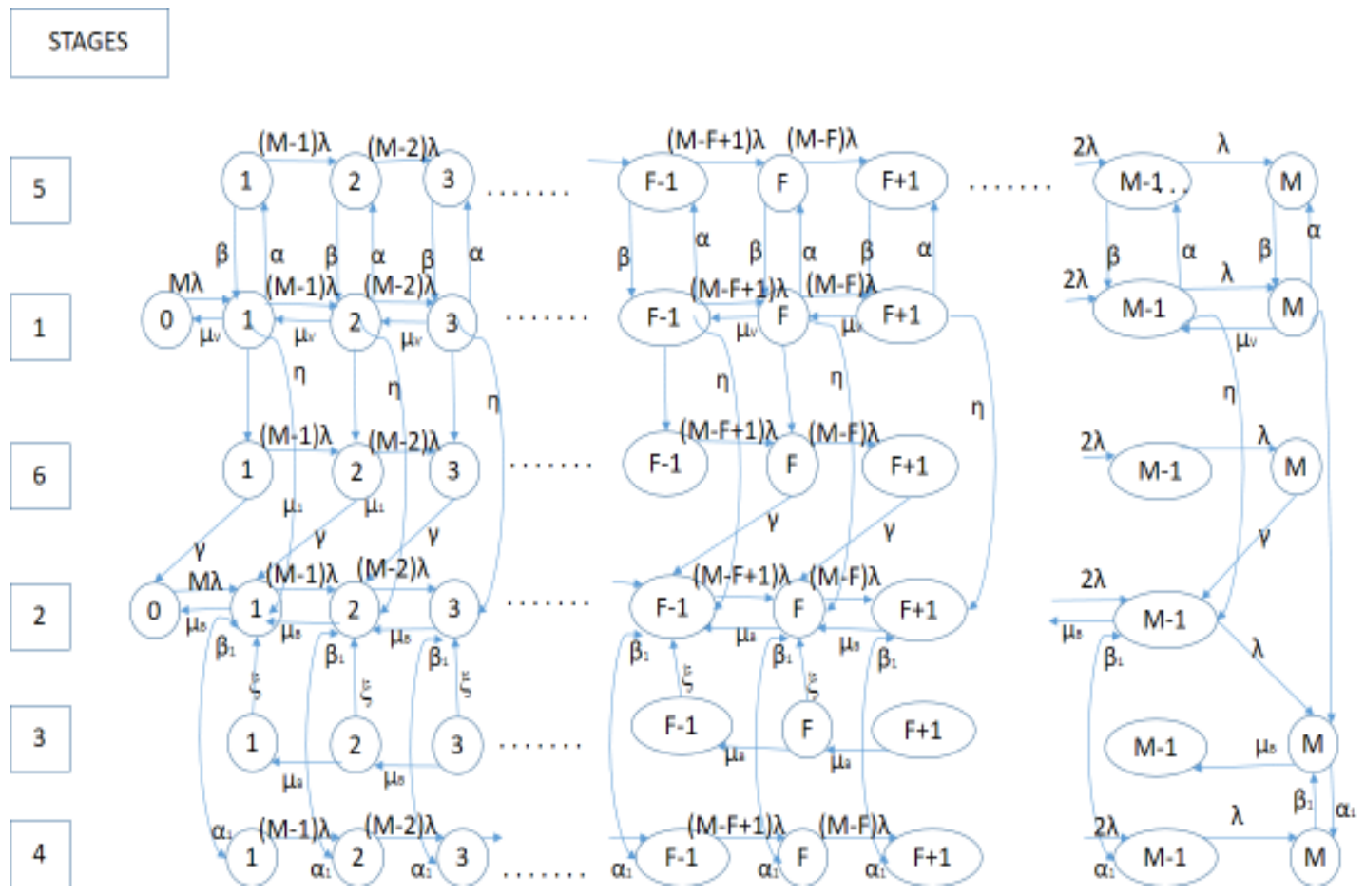

Figure 1. State transition diagram

\subsection{Application to Automobile Repair Shop (ARS)}

The present model can be easily demonstrated by taking a realistic situation of Automobile repair shop (ARS). ARS is an establishment where automobiles are repaired by technicians (server). An ARS is basically finite capacity system (space limitation) where a finite number of automobiles can be accommodated at a time. Moreover, in order to control the arrival of the customers (i.e. machines requiring repair), the incoming customers are stopped to enter the workshop area i.e. ARS if capacity is full and their arrival is started when a certain threshold number of customers say ' $F$ ' has been left in the area for service. This pattern namely F-policy is followed in almost every realistic situation where a controlled arrival is appreciated. The repairman (server) also goes for working vacation (like lunch breaks, rest hours) where instead of completely shutting down the services, he prefers to continue the service at lower rates as usual. It happens with automobile repair shop or any industrial problem where services are stopped for a certain duration (known as vacation) but when server prefer to serve even during rest hours it is termed as working vacation. The failed machines on finding the server busy join the orbit and try for the service. Automobile repair shop can be modelled as real life examples of retrial queueing models. A basic schematic diagram depicting model is shown below in Figure 2 as: 


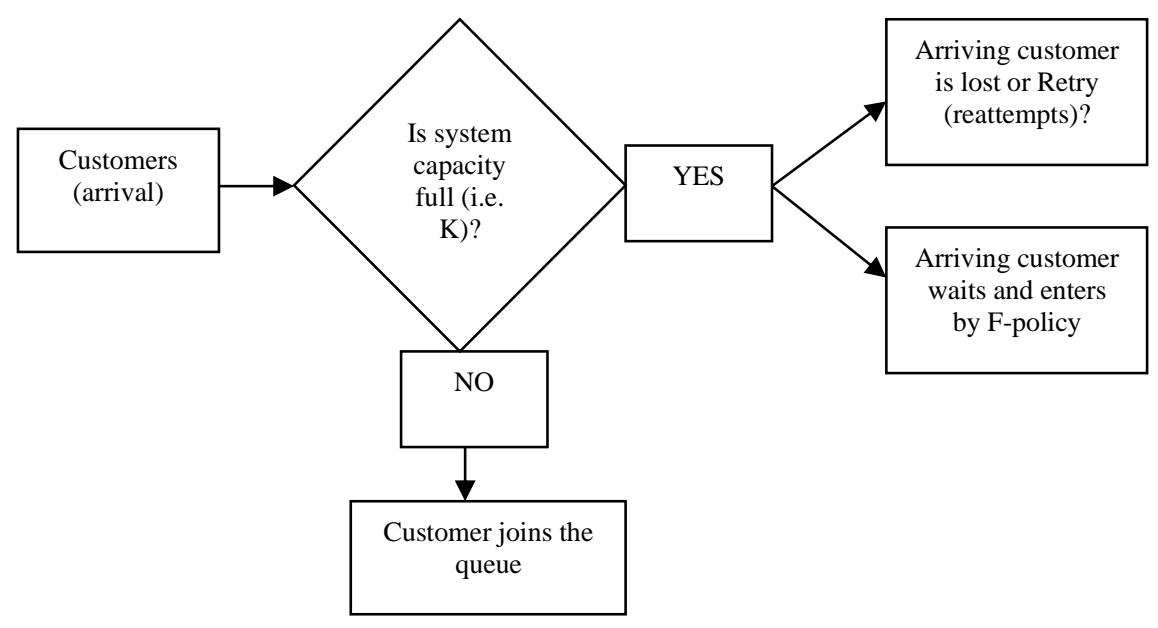

Figure 2. Schematic diagram for automobile repair shop (ARS) model

\section{Model Formulation}

The time dependent probabilities are defined as $P_{i, n}(t)$ where, $i \in\{1,2,3,4,5\}, n$ corresponds to the count of failed machines in the system at time t, $n=0,1,2, \ldots, M$ and $i(t)$ stands for the status of the server at any time $t$. Now, we define different states of the server $i(t)$ as

$$
i(t)=\left\{\begin{array}{l}
1, \text { working vacation } \\
2(3), \text { normal busy period, arrivals allowed }(\text { not allowed) } \\
4, \text { breakdown during normal busy period } \\
5, \text { breakdown during working vacation } \\
6, \text { retrial state }
\end{array}\right.
$$

The standard time dependent equations for various states of Machine repair problem under study are constructed as follows:

(i) When $i=1$

$P_{1,0}^{\prime}(t)=\mu_{v} P_{1,1}(t)-(M \lambda+\eta) P_{1,0}(t)$

$P_{1, n}^{\prime}(t)=\beta P_{5, n}(t)+(M-(n-1)) \lambda P_{1, n-1}(t)+\mu_{v} P_{1, n+1}(t)-\left(\alpha+\eta+\mu_{v}+\eta+(M-n) \lambda\right) P_{1, n}(t)$

$1 \leq n \leq M-1$

$P_{1, M}^{\prime}(t)=\beta P_{5, M}(t)+\lambda P_{1, M-1}(t)-\left(\mu_{v}+\alpha+\eta\right) P_{1, M}(t)$ 
International Journal of Mathematical, Engineering and Management Sciences

Vol. 6, No. 1, 279-295, 2021

https://doi.org/10.33889/IJMEMS.2021.6.1.018

(ii) When $i=2$

$$
\begin{aligned}
& P_{2,0}^{\prime}(t)=\mu_{B} P_{2,1}(t)+\eta P_{1,0}(t)+\gamma P_{6,1}(t)-M \lambda P_{2,0}(t) \\
& P_{2, n}^{\prime}(t)=\mu_{B} P_{2, n+1}(t)+\eta P_{1, n+1}(t)+\gamma P_{6, n+1}(t)+\beta_{1} P_{4, n}(t)+ \\
& (M-(n-1)) \lambda P_{2, n-1}(t)+\xi P_{3, n}(t)-\left(\mu_{B}+(M-n) \lambda+\alpha_{1}\right) P_{2, n}(t) ; \quad n=1, \ldots ., F \\
& P_{2, n}^{\prime}(t)=\mu_{B} P_{2, n+1}(t)+\eta P_{1, n+1}(t)+\gamma P_{6, n+1}(t)+\beta_{1} P_{4, n}(t)+(M-(n-1)) \lambda P_{2, n-1}(t)- \\
& \left(\mu_{B}+(M-n) \lambda+\alpha_{1}\right) P_{2, n}(t) ; \quad n=F+1, \ldots \ldots, M-1 \\
& P_{2, M-1}(t)=\beta_{1} P_{4, M-1}(t)+\eta P_{1, M-1}(t)+\gamma P_{6, M}(t)+(M-\lambda) P_{2, M-2}(t)-\left(\lambda+\mu_{B}+\alpha_{1}\right) P_{2, M-1}(t)
\end{aligned}
$$

(iii) When $i=3$

$$
\begin{aligned}
& P_{3,1}^{\prime}(t)=\mu_{B} P_{3,2}(t)-\xi P_{3,1}(t) \\
& P_{3, n}^{\prime}(t)=\mu_{B} P_{3, n+1}(t)-\left(\mu_{B}+\xi\right) P_{3, n}(t) ; n=2, \ldots . ., F \\
& P_{3, n}^{\prime}(t)=\mu_{B} P_{3, n+1}(t)-\mu_{B} P_{3, n}(t) ; n=F+1, \ldots . ., M-1 \\
& P_{3, M}^{\prime}(t)=\eta P_{1, M}(t)+\lambda P_{2, M-1}(t)+\beta_{1} P_{4, M}(t)-\left(\alpha_{1}+\mu_{B}\right) P_{3, M}(t)
\end{aligned}
$$

(iv) When $i=4$

$$
\begin{aligned}
& P_{4,1}^{\prime}(t)=\alpha P_{2,1}(t)-\left(\beta_{1}+(M-1) \lambda\right) P_{4,1}(t) \\
& P_{4, n}^{\prime}(t)=\alpha_{1} P_{2, n}(t)+\left((M-(n-1) \lambda) P_{4, n-1}(t)-\left(\beta_{1}+(M-n) \lambda\right) P_{4, n}(t) ; 2 \leq n \leq M-1\right. \\
& P_{4, M}^{\prime}(t)=\lambda P_{4, M-1}(t)+\alpha_{1} P_{3, M}(t)-\beta P_{4, M}(t)
\end{aligned}
$$

(v) When $i=5$

$$
\begin{aligned}
& P_{5,1}^{\prime}(t)=\alpha P_{1,1}(t)-(\beta+(M-1) \lambda) P_{5,1}(t) \\
& P_{5, n}^{\prime}(t)=\alpha P_{1, n}(t)+\left((M-(n-1) \lambda) P_{5, n-1}(t)-(\beta+(M-n) \lambda) P_{5, n}(t) ; 2 \leq n \leq M-1\right. \\
& P_{5, M}^{\prime}(t)=\lambda P_{5, M-1}(t)+\alpha P_{1, M}(t)-\beta P_{5, M}(t)
\end{aligned}
$$

(vi) When $i=6$

$$
P_{6,1}^{\prime}(t)=-(\gamma+(M-1) \lambda) P_{6,1}(t)
$$


International Journal of Mathematical, Engineering and Management Sciences

Vol. 6, No. 1, 279-295, 2021

https://doi.org/10.33889/IJMEMS.2021.6.1.018

$$
\begin{aligned}
& P_{6, n}^{\prime}(t)=(M-(n-1)) \lambda P_{6, n-1}(t)-(\gamma+(M-n) \lambda) P_{6, n}(t) ; 2 \leq n \leq M-1 \\
& P_{6, M}^{\prime}(t)=\lambda P_{6, M-1}(t)-\gamma P_{6, M}(t)
\end{aligned}
$$

and,

$$
\sum_{n=1}^{M} \sum_{i=1}^{5} P_{i, n}(t)=1
$$

\section{Performance Measures}

The performance of the machining system can be measured in terms of performance measures that reveal the efficiency of the system in various situations.

\subsection{Reliability and Queueing Measures}

The reliability and queueing measures are significant in exhibiting the efficiency of a model. Reliability measures like failure frequency, availability gives information about the probability of a system being reliable and available for services, whereas queueing measures correspond to important measures like queue length. Some of them are summarized as:

(i) Queue length of failed operating units in the system

$$
L_{s}(t)=\sum_{i=3}^{6} \sum_{n=1}^{M} n P_{i, n}(t)+\sum_{n=1}^{M} P_{1, n}(t)+\sum_{n=1}^{M-1} P_{2, n}(t)
$$

(ii) Failure frequency

$$
F_{f}(t)=\alpha \sum_{n=0}^{M} P_{1, n}(t)+\alpha \sum_{n=0}^{M-1} P_{2, n}(t)
$$

(iii) Expected waiting time of failed machines

$$
W(t)=E[N(t)] \div \lambda
$$

(iv) Throughput of the system

$$
T P(t)=\mu_{v} \sum_{n=0}^{M} P_{1, n}(t)+\mu_{B} \sum_{n=1}^{M} P_{2, n}(t)
$$

\subsection{State Probabilities}

The state probabilities usually refer to the probability of server in specific states. They give more precise information about server performance in different subsets. Some of them can be expressed as follows: 
International Journal of Mathematical, Engineering and Management Sciences

Vol. 6, No. 1, 279-295, 2021

https://doi.org/10.33889/IJMEMS.2021.6.1.018

(i) Busy state while providing services in working vacation

$$
P_{V}(t)=\sum_{n=0}^{M} P_{1, n}(t)
$$

(ii) Busy state while providing services in normal busy period

$$
P_{B}(t)=\sum_{n=0}^{M-1} P_{2, n}(t)+\sum_{n=1}^{M} P_{3, n}(t)
$$

(iii) Busy State

$$
P_{C}(t)=\sum_{n=0}^{M-1} P_{2, n}(t)+\sum_{n=1}^{M} P_{3, n}(t)+\sum_{n=0}^{M} P_{1, n}(t)
$$

(iv) Retrial state

$$
P_{R}(t)=\sum_{n=1}^{M} P_{6, n}(t)
$$

(v) Probability of being available for providing service

$$
P_{A}(t)=\sum_{n=1}^{M} P_{1, n}(t)+\sum_{n=1}^{M-1} P_{2, n}(t)
$$

(vi) State when customers are allowed to enter the system

$$
P_{Z}(t)=\sum_{n=1}^{F} P_{3, n}(t)
$$

(vii) State of being failed and under repair

$$
P_{Q}(t)=\sum_{n=1}^{M} P_{5, n}(t)+\sum_{n=4}^{M} P_{4, n}(t)
$$

(viii) Repair state

$$
P_{R E}(t)=\sum_{i=4}^{5} \sum_{n=1}^{M} P_{i, n}(t)
$$

\section{Numerical Results}

Here, the Runge-Kutta (R-K) method is implemented to study the performances measures of the model numerically. The choice of using this particular numerical scheme is due to its efficiency to give more stable results. For example, if $h$ is the step size, then local truncation error for other 
International Journal of Mathematical, Engineering and Management Sciences

Vol. 6, No. 1, 279-295, 2021

https://doi.org/10.33889/IJMEMS.2021.6.1.018

methods like Euler's method is $\mathrm{h}^{2}$, where as for R-K method of $4^{\text {th }}$ order it is $\mathrm{h}^{5}$ which leads to more efficient results. The sensitivity of various performance measures towards different parameters have been shown through graphs and tables. The default parameters have been chosen as $\mu_{V}=0.1$; $\alpha=0.01 ; \alpha_{1}=0.02 ; \lambda=20 ; \beta=0.2 ; \beta_{1}=0.3 ; \xi=0.1 ; \mu_{b}=0.6 ; \eta=0.2 ; \gamma=0.1$.

\section{A. State Probabilities}

Here, in this subsection the sensitivity of state probabilities with various parameters like breakdown rate, service rate and repair rate has been examined.

\section{(a) Breakdown Rate $\alpha$ vs. State Probabilities}

The effect of $\alpha$ on server's state probabilities namely $P_{Z}(t)$ (when server allow the arrival) and $P_{Q}(t)$ (probability of being failed and under repair) is shown in Table 1. As the breakdown rate increases from 0.01 to 0.05 , the service processes is lowered and speed to reach upto threshold value say $\mathrm{F}$ decreases. This in turn reduces $P_{Z}(t)$. But on the other hand, a growth in breakdown rate increases the value of $P_{Q}(t)$ which is obvious. With an increase in service rate, corresponding values of $P_{Z}(t)$ increases whereas $P_{Q}(t)$ decreases.

\section{(b) Repair Rate $\beta$ vs. State Probabilities}

Table 2 shows the effect of repair rate $\beta$ on state probabilities. As the repair rate increases from $\beta$ $=0.2$ to 0.4 units, then the probability of the server in repair state $P_{Q}(t)$ decreases. Moreover, the probability of server being busy in providing service $P_{B}(t)$ increases although to a very smaller extent. But as time duration increases from $t=5$ to 15 units, the values of $P_{B}(t)$ decreases.

Table 1. Effect of $\alpha$ on state probabilities

\begin{tabular}{|c|c|c|c|c|c|}
\hline & & $\mathbf{\alpha}=\mathbf{0 . 0 1}$ & & $\boldsymbol{\alpha}=\mathbf{0 . 0 5}$ & $P_{Q}(t)$ \\
\hline $\boldsymbol{t}$ & $\boldsymbol{\mu}$ & $\boldsymbol{P}_{Z}(\boldsymbol{t})$ & $\boldsymbol{P}_{Q}(\boldsymbol{t})$ & $\boldsymbol{P}_{Z}(\boldsymbol{t})$ & 0.0117 \\
\hline & $\mathbf{2}$ & 0.9853 & 0.0024 & 0.9294 & 0.0095 \\
\hline $\mathbf{5}$ & $\mathbf{3}$ & 0.9879 & 0.0019 & 0.9417 & 0.0081 \\
\hline \hline & $\mathbf{4}$ & 0.9898 & 0.0016 & 0.9505 & 0.0125 \\
\hline $\mathbf{1 0}$ & $\mathbf{2}$ & 0.9822 & 0.0026 & 0.9157 & 0.0098 \\
\hline & $\mathbf{3}$ & 0.9854 & 0.0021 & 0.9302 & 0.0081 \\
\hline \hline & $\mathbf{4}$ & 0.9877 & 0.0018 & 0.9406 & 0.0127 \\
\hline $\mathbf{1 5}$ & $\mathbf{3}$ & 0.9805 & 0.0028 & 0.9105 & 0.0099 \\
\hline & $\mathbf{4}$ & 0.9844 & 0.0023 & 0.9259 & 0.0082 \\
\hline
\end{tabular}


International Journal of Mathematical, Engineering and Management Sciences

Vol. 6, No. 1, 279-295, 2021

https://doi.org/10.33889/IJMEMS.2021.6.1.018

Table 2. Effect of $\beta$ on state probabilities

\begin{tabular}{|c|c|c|c|c|c|}
\hline & & $\boldsymbol{\beta}=\mathbf{0 . 2}$ & & $\boldsymbol{\beta}=\mathbf{0 . 4}$ & $\boldsymbol{P}_{B}(\boldsymbol{t})$ \\
\hline $\boldsymbol{t}$ & $\boldsymbol{\mu}$ & $\boldsymbol{P}_{\boldsymbol{B}}(\boldsymbol{t})$ & $\boldsymbol{P}_{Q}(\boldsymbol{t})$ & 0.000006 & 0.002318 \\
\hline & $\mathbf{2}$ & 0.000005 & 0.004300 & 0.000002 & 0.000019 \\
\hline $\mathbf{5}$ & $\mathbf{3}$ & 0.000001 & 0.003000 & 0.000001 & 0.001257 \\
\hline \hline & $\mathbf{4}$ & 0.000001 & 0.002300 & 0.000013 & 0.003433 \\
\hline $\mathbf{1 0}$ & $\mathbf{2}$ & 0.000012 & 0.008100 & 0.000005 & 0.002436 \\
\hline & $\mathbf{3}$ & 0.000005 & 0.005700 & 0.000003 & 0.001891 \\
\hline \hline & $\mathbf{4}$ & 0.000003 & 0.004400 & 0.000016 & 0.003704 \\
\hline $\mathbf{1 5}$ & $\mathbf{3}$ & 0.000018 & 0.009700 & 0.000006 & 0.002635 \\
\hline & $\mathbf{4}$ & 0.000008 & 0.006900 & 0.000003 & 0.002047 \\
\hline
\end{tabular}

\section{B. Queue Length}

Queue length is one of the significant performance measure that draw attention of many architects, industrialists etc. as it decides in optimal management of waiting customers in terms of space. The variation in the queue length w.r.t. different parameters is shown by figures 3-5. Figure 3 is plotted between time $t$ and $L_{S}(t)$ corresponding to different values of $\lambda$. It is quite obvious that an increase in arrival rate will automatically increase the queue length of the system and same is exhibited by Figure 3 . The number of failed machines increases as arrival rate $\lambda$ increases.

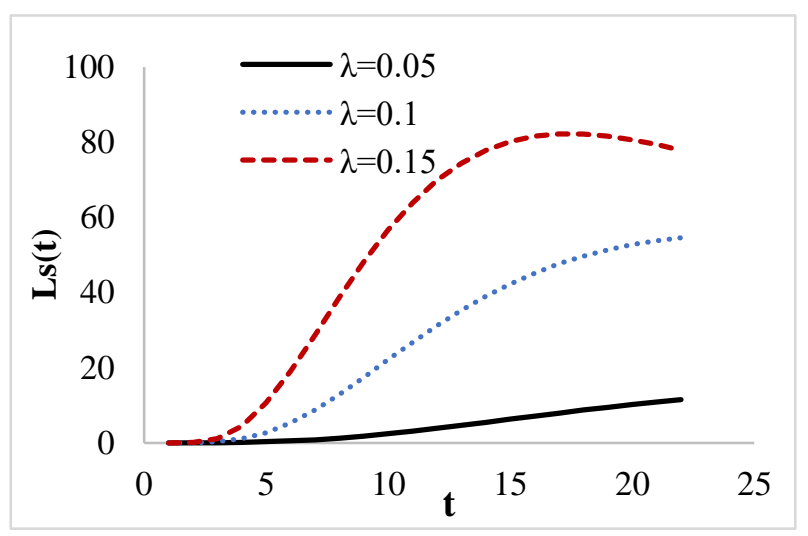

Figure 3. Effect of $\lambda$ on $L_{S}(t)$ 
International Journal of Mathematical, Engineering and Management Sciences

Vol. 6, No. 1, 279-295, 2021

https://doi.org/10.33889/IJMEMS.2021.6.1.018

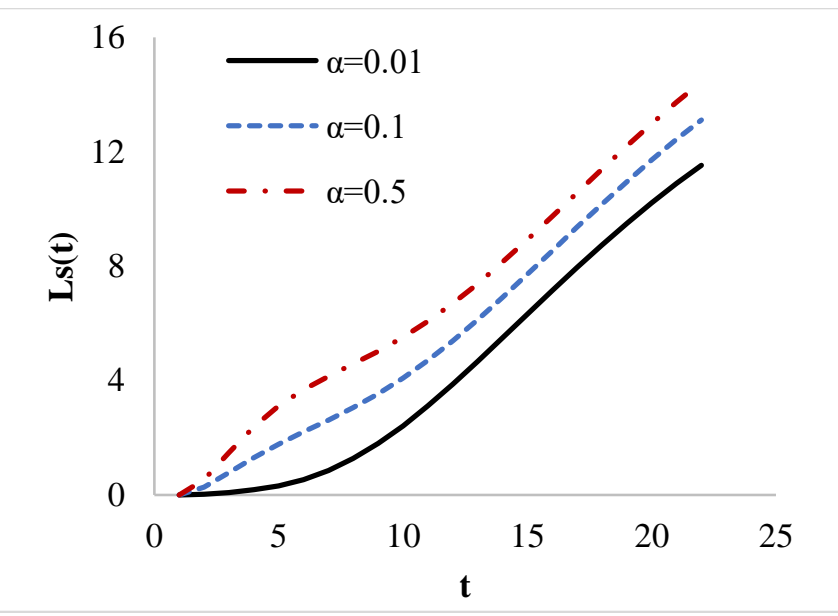

Figure 4. Effect of $\alpha$ on $L_{S}(t)$

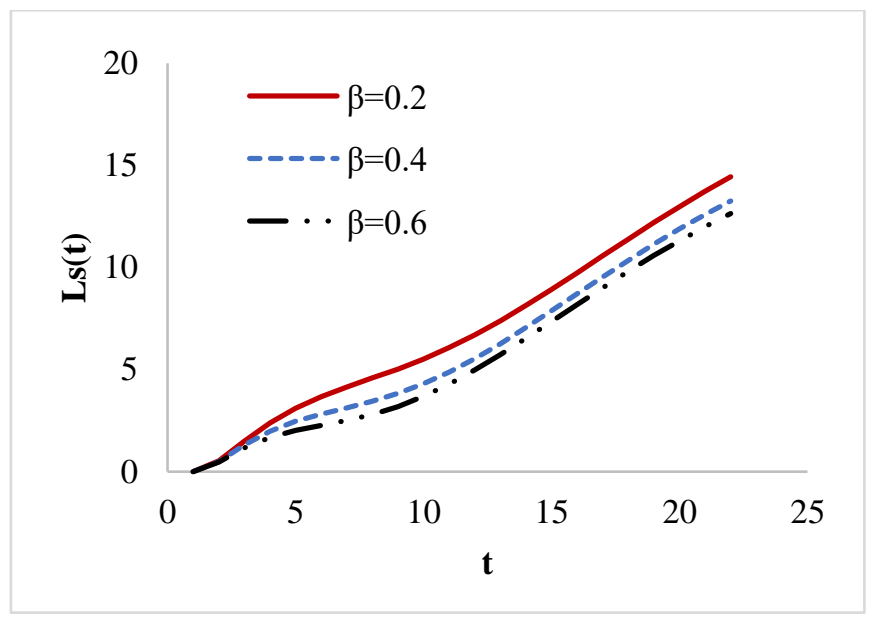

Figure 5. Effect of $\beta$ on $L_{S}(t)$

Figures 4 and 5 demonstrate the sensitivity of $L_{S}(t)$ with breakdown rate $(\alpha)$ and repair rate $(\beta)$ during normal busy period respectively. An increase in failure rate $\alpha$ triggers the number of failed machines in the system. Thus, a control on the failure rate of the server can help in early services leading to shorter queue lengths of failed machines for service. Figure 5 demonstrates the variation in $L_{S}(t)$ with different values of repair rate with time $t$. It is clear from the figure 5 that a hike in repair rate from 0.2 to 0.4 units leads to decrement in $L_{S}(t)$ as higher values of $\beta$ speeds up service.

\section{Failure Frequency}

Failure frequency is one of the reliability measures for any model that basically depicts the tendency of a server to fail while servicing and actually indicate its reliability. Figure 6 displays the effect of on failure frequency $F_{f}(t)$. It can be observed from Figure 6 that as the breakdown rate increases 
International Journal of Mathematical, Engineering and Management Sciences

Vol. 6, No. 1, 279-295, 2021

https://doi.org/10.33889/IJMEMS.2021.6.1.018

the probability of the server being in failure state also increases. Hence, a control over the breakdown rate can be of immense help in reducing failure frequency of any system.

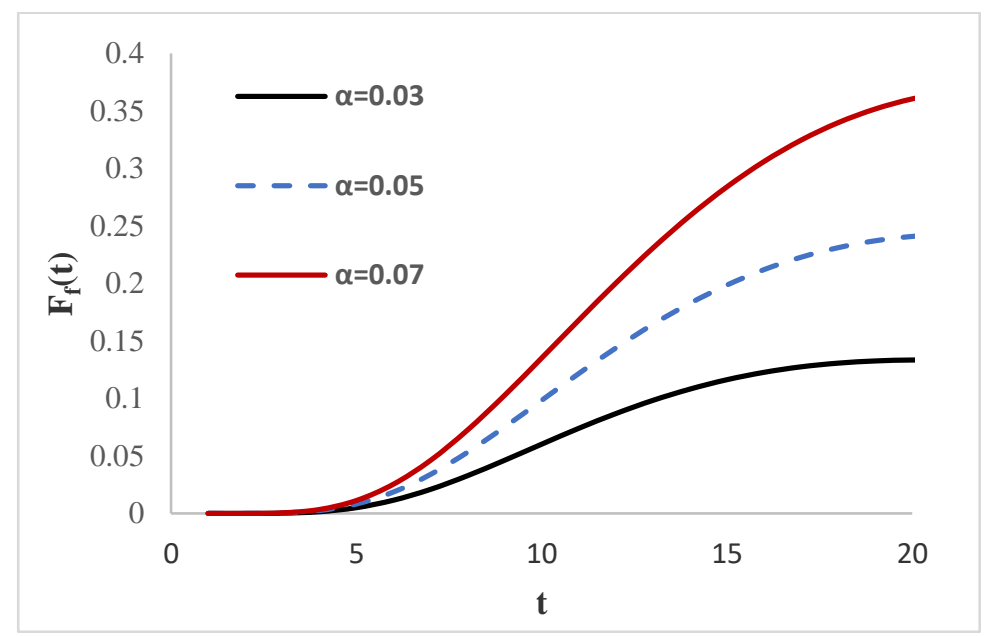

Figure 6. Effect of $\alpha$ on failure frequency

\section{Throughput}

Throughput usually refers to the number of effective services provided to the customers. Figures 7-8 are plotted to depict the effect of the service rate on the system throughput. It is observed from the figures that with an increase in the service rate, more services are offered to the customers while servicing.

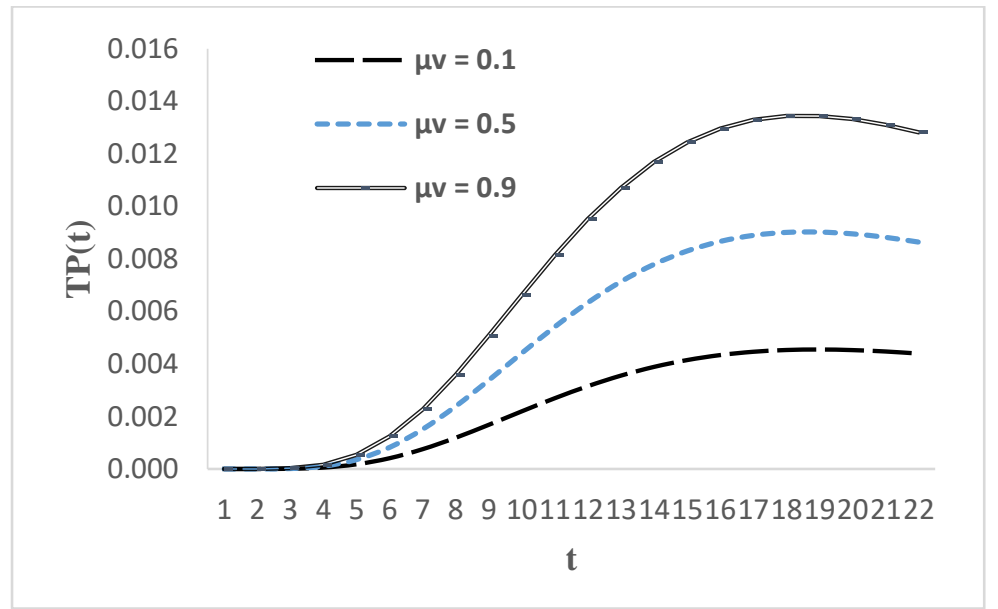

Figure 7. Effect of $\mu_{V}$ on $T P(t)$ 
International Journal of Mathematical, Engineering and Management Sciences

Vol. 6, No. 1, 279-295, 2021

https://doi.org/10.33889/IJMEMS.2021.6.1.018

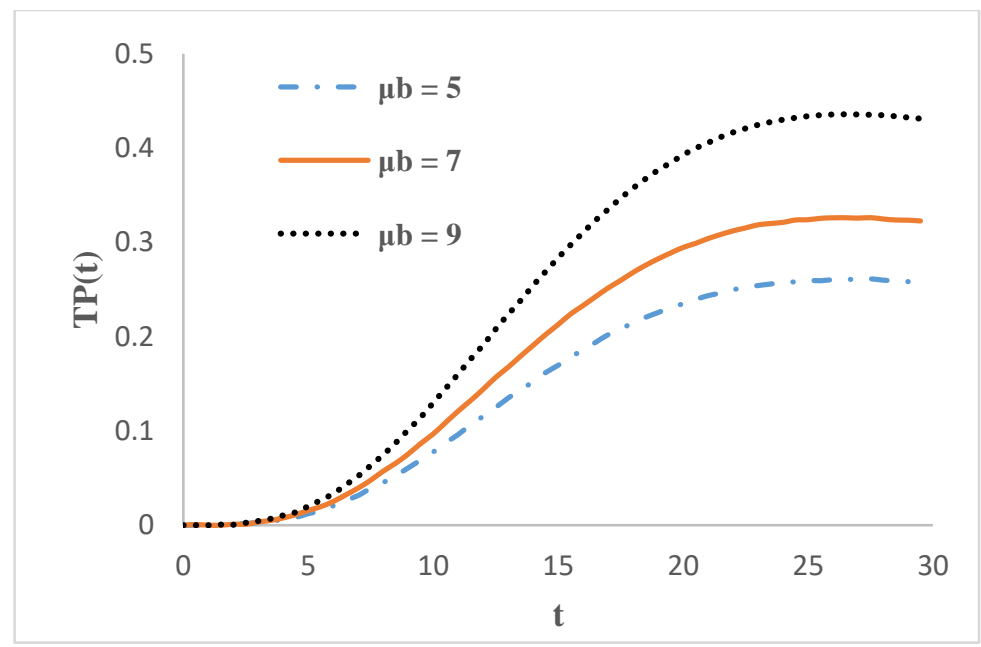

Figure 8. Effect of $\mu_{b}$ on $T P(t)$

\section{Cost Function and Analysis}

Cost sustained on any system is most common factor that system managers address in real life situations. A particular designer targets to design queueing system which is economic in terms of money. The cost function is as:

$$
\mathrm{TC}(\mathrm{t})=\mathrm{C}_{\mathrm{B}} \mathrm{P}_{\mathrm{C}}(\mathrm{t})+\mathrm{C}_{\mathrm{h}} \mathrm{L}_{\mathrm{s}}(\mathrm{t})+\mathrm{C}_{\mathrm{R}} \mathrm{P}_{\mathrm{Q}}(\mathrm{t})+\xi \mathrm{C}_{\mathrm{S}}+\gamma \mathrm{C}_{\mathrm{RE}}+\mathrm{C}_{1} \mu_{\mathrm{v}}(\mathrm{t})+\left(\mathrm{C}_{2}+C_{3}\right) \mu_{\mathrm{b}}(\mathrm{t})
$$

Different cost notations used in equation (34) can be narrated below as:

$\mathrm{C}_{\mathrm{B}}$ : Cost per unit time when server is busy

$\mathrm{C}_{\mathrm{h}}$ : Holding cost for customer per unit time

$\mathrm{C}_{\mathrm{R}}$ : Cost per unit time when server is under repair

$\mathrm{C}_{\mathrm{RE}}$ : fixed cost for customer who retry for service

$\mathrm{C}_{\mathrm{S}}$ : Fixed cost for start-up process when customers are allowed to enter

$\mathrm{C}_{1}$ : Cost for servicing during working vacation

$\mathrm{C}_{2}$ : Cost for servicing when arrivals are allowed during normal busy period

$C_{3}$ : Cost for servicing when arrivals are not allowed during normal busy period.

For numerical purposes, we consider default values of cost set as:

$\mathrm{C}_{\mathrm{h}}=5 ; \mathrm{C}_{\mathrm{B}}=300 ; \mathrm{C}_{1}=200 ; \mathrm{C}_{\mathrm{S}}=300 ; \mathrm{C}_{\mathrm{R}}=60 ; C_{3}=15 ; \mathrm{C}_{2}=150 ; \mathrm{C}_{\mathrm{RE}}=200$.

This set of cost values is taken based on the literature available on similar modelling. Moreover, these cost values also have some practical approach too. Likewise for an example, $\mathrm{C}_{\mathrm{h}}$ is taken as 5 units whereas $C_{1}$ is taken as 200 units which is far more as compared to $C_{h}$. This is because, holding cost is incurred on the system when customer waits for the service and use already built in services 
International Journal of Mathematical, Engineering and Management Sciences

Vol. 6, No. 1, 279-295, 2021

https://doi.org/10.33889/IJMEMS.2021.6.1.018

of the system (like space, seating spaces etc.) and of course has to be less in comparison to the cost of providing services. The ratio of differences can vary from system to system.

The total cost efficiency has been determined by breakdown rate, repair time, service time and arrival rate. In figures 9-12, the effectiveness of expected cost towards various parameters has been shown. Figure 9 depicts variation in total cost with $\alpha$. As the value of $\alpha$ increases from 1 to 3 units the total cost $\mathrm{TC}(\mathrm{t})$ decreases and with a hike in arrival rate, $\mathrm{TC}(\mathrm{t})$ decreases. Figure 10 gives the variation of total cost with repair rate. It is clear from the Figure 11 that with an increase in the service provided by the system the total system cost increases. From Figure 12, it is observed that there is decrement in $\mathrm{TC}(\mathrm{t})$ as the arrival rate increases.

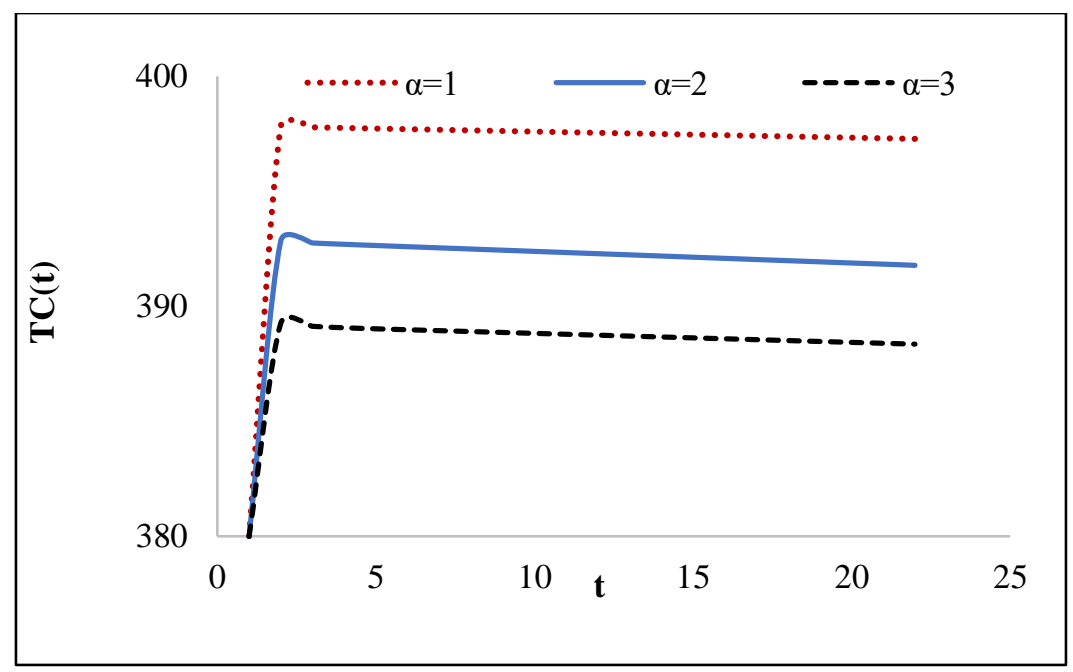

Figure 9. $T C(t)$ vs. $\alpha$

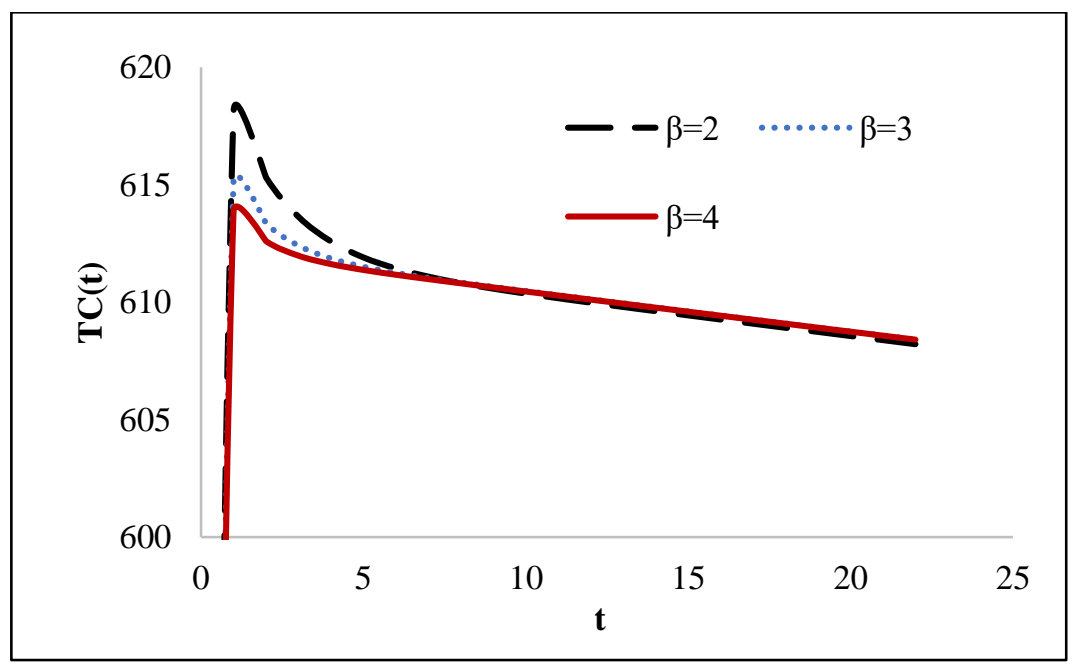

Figure 10. $T C(t)$ vs. $\beta$ 
International Journal of Mathematical, Engineering and Management Sciences

Vol. 6, No. 1, 279-295, 2021

https://doi.org/10.33889/IJMEMS.2021.6.1.018

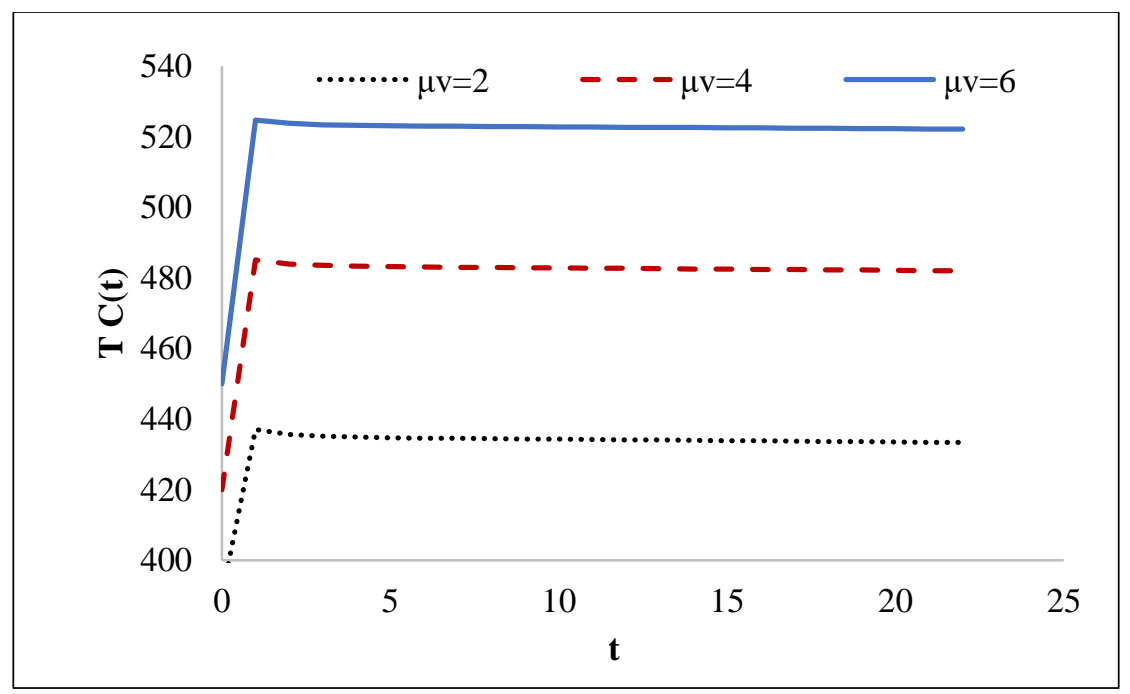

Figure 11. $T C(t)$ vs. $\mu_{V}$

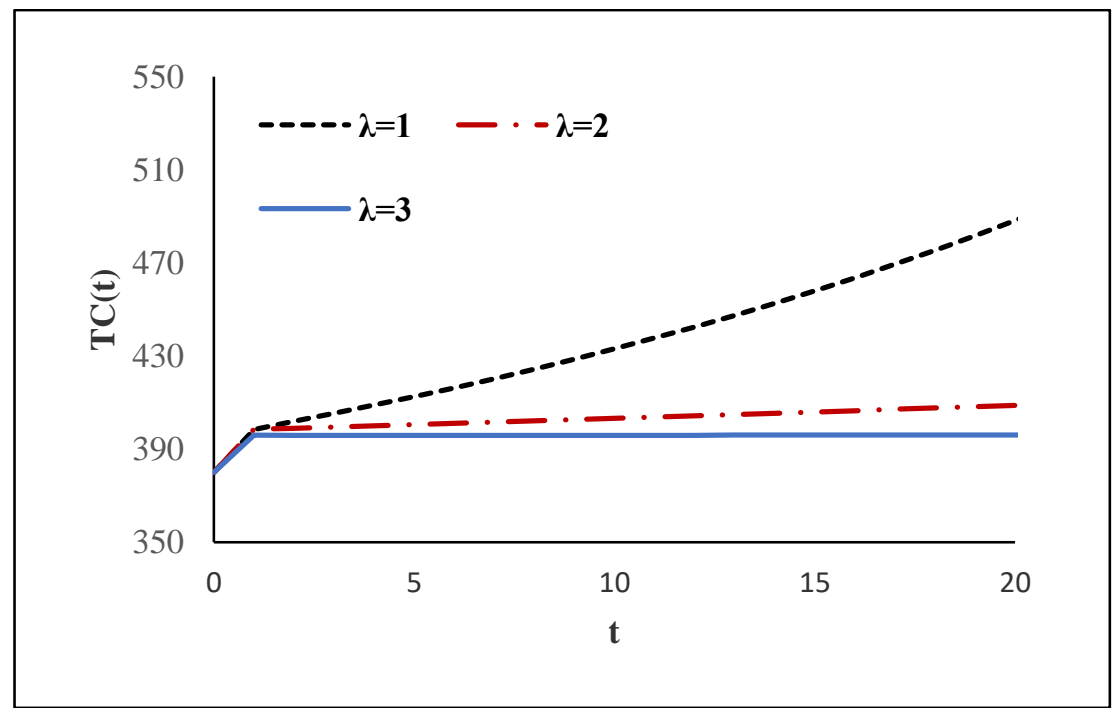

Figure 12. $T C(t)$ vs. $\lambda$

\section{Conclusions}

With the remarkable advancement in the technology and passage of time, machines have become lifeline of human lives. So, machine repair problem holds a significant place with variety of realistic applications associated to their modelling and so thus their investigations. The retrial based machine repair model incorporated with various significant situations like working vacation, breakdown etc. has been studied. Based on our investigation on unreliable machine repair model with retrial, it can be inferred that maintenance of broken machines should be performed timely to make the device work smoothly. To overcome the problem of long queues, service rate has to be 
International Journal of Mathematical, Engineering and Management Sciences

Vol. 6, No. 1, 279-295, 2021

https://doi.org/10.33889/IJMEMS.2021.6.1.018

increased but it will result in the increase in service cost. For better utilization of the server the concept of working vacation has been applied so that server can repair the machines with slow rate during vacation period. A variety of queueing and reliability measures have also been determined and sensitivity analysis has been done in various contexts. There is also a possible scope for the further investigations of such type of queueing problems. Machine repair problem with reattempts considered here can further be studied in context with other control policies like N-policy and threshold policy. Also, arrival of two types of machines basically dealing with priority services can also be considered as future scope with an insight to manufacturing applications. Queueing models with different maintenance policies are useful in solving the problem of delay in industrial systems.

\section{Conflict of Interest}

The authors confirm that there is no conflict of interest to declare for this publication.

\section{Acknowledgments}

The authors would like to appreciate the effort from editors and reviewers. This study received no specific grant from government, commercial or non-profit funding organizations.

\section{References}

Artalejo, J.R. (1999). A classified bibliography of research on retrial queues : progress in 1990-1999. Top, $7(2), 187-211$.

Artalejo, J.R. (2010). Accessible bibliography on retrial queues: progress in 2000-2009. Mathematical and Computer Modelling, 51(9-10), 1071-1081.

Bhagat, A. (2020, March). Unreliable priority retrial queues with double orbits and discouraged customers. In AIP Conference Proceedings (Vol. 2214, No. 1, p. 020014). AIP Publishing. https://doi.org/10.1063/5.0003372.

Chandrasekaran, V.M., Indhira, K., Saravanarajan, M.C., \& Rajadurai, P. (2016). A survey on working vacation queueing models. International Journal of Pure and Applied Mathematics, 106(6), 33-41.

Choudhury, G., \& Ke, J.C. (2014). An unreliable retrial queue with delaying repair and general retrial times under Bernoulli vacation schedule. Applied Mathematics and Computation, 230, 436-450.

Falin, G. (1990). A survey of retrial queues. Queueing Systems, 7(2), 127-167.

Jain, M., \& Bhagat, A. (2015). Transient analysis of finite F-policy retrial queues with delayed repair and threshold recovery. National Academy Science Letters, 38(3), 257-261.

Jain, M., Sharma, G.C., \& Sharma, R. (2012). Optimal control of (N, F) policy for unreliable server queue with multi-optional phase repair and start-up. International Journal of Mathematics in Operational Research, 4(2), 152-174.

Jain, M., \& Singh, M. (2020). Transient analysis of a Markov queueing model with feedback, discouragement and disaster. International Journal of Applied and Computational Mathematics, 6(2), 1-14.

Ke, J.C., Hsu, Y.L., Liu, T.H., \& George Zhang, Z. (2013). Computational analysis of machine repair problem with unreliable multi-repairmen. Computers and Operations Research, 40(3), 848-855.

Levy, Y., \& Yechiali, U. (1975). Utilization of idle time in an M/G/1 queueing system. Management Science, 22(2), 202-211.

Li, T., \& Zhang, L. (2017). An M/G/1 retrial G-queue with general retrial times and working breakdowns. Mathematical and Computational Applications, 22(1), 1-15. 
International Journal of Mathematical, Engineering and Management Sciences

Vol. 6, No. 1, 279-295, 2021

https://doi.org/10.33889/IJMEMS.2021.6.1.018

Morozov, E., \& Phung-Duc, T. (2017). Stability analysis of a multiclass retrial system with classical retrial policy. Performance Evaluation, 112, 15-26.

Servi, L.D., \& Finn, S.G. (2002). M/M/1 queues with working vacations (M/M/1/WV). Performance Evaluation, 50(1), 41-52.

Sethi, R., Jain, M., Meena, R.K., \& Garg, D. (2020). Cost optimization and ANFIS computing of an unreliable M/M/1 queueing system with customers' impatience under N-policy. International Journal of Applied and Computational Mathematics, 6(2), 1-14.

Sethi, R., \& Bhagat, A. (2019, January). Performance analysis of machine repair problem with working vacation and service interruptions. In AIP Conference Proceedings (Vol. 2061, No. 1, p. 020028). AIP Publishing. https://doi.org/10.1063/1.5086650.

Sethi, R., Bhagat, A., \& Garg, D. (2019). ANFIS based machine repair model with control policies and working vacation. International Journal of Mathematical, Engineering and Management Sciences, 4(6), $1522-1533$.

Sharma, R., \& Kumar, G. (2017). Availability improvement for the successive K-out-of-N machining system using standby with multiple working vacations. International Journal of Reliability and Safety, 11(3-4), 256-267.

Sharma, R., \& Kumar, G. (2020, February). Multi-server M/M/c queue and multiple working vacation under phase repair. In 2020 3rd International Conference on Emerging Technologies in Computer Engineering: Machine Learning and Internet of Things (ICETCE) (pp. 181-185). IEEE. Jaipur, India.

Shekhar, C., Raina, A.A., \& Kumar, A. (2016). A brief review on retrial queue: progress in 2010-2015. International Journal of Applied Sciences and Engineering Research, 5(4), 324-336.

Shekhar, C., Raina, A.A., Kumar, A., \& Iqbal, J. (2017). A survey on queues in machining system: progress from 2010 to 2017. Yugoslav Journal of Operations Research, 27(4), 391-413.

Sherman, N.P., \& Kharoufeh, J.P. (2006). An M/M/1 retrial queue with unreliable server. Operations Research Letters, 34(6), 697-705.

Wang, K.H., \& Yang, D.Y. (2009). Controlling arrivals for a queueing system with an unreliable server: Newton-Quasi method. Applied Mathematics and Computation, 213(1), 92-101.

Wang, K.H., Chen, W.L., \& Yang, D.Y. (2009). Optimal management of the machine repair problem with working vacation: Newton's method. Journal of Computational and Applied Mathematics, 233(2), 449458 .

Wu, C.H., Lee, W.C., Ke, J.C., \& Liu, T.H. (2014). Optimization analysis of an unreliable multi-server queue with a controllable repair policy. Computers and Operations Research, 49, 83-96.

Original content of this work is copyright (C) International Journal of Mathematical, Engineering and Management Sciences. Uses under the Creative Commons Attribution 4.0 International (CC BY 4.0) license at https://creativecommons.org/licenses/by/4.0/ 